\title{
Textile Logics of Late Medieval Romance TOM WHITE
}

\section{Birkbeck, University of London}

Abstract: This essay examines some of the threads linking textiles, late medieval vernacular romance, and the manuscripts in which they survive. The metaphor of the fabric fold or gathering for the composition of romance evokes the shared Latin etymology of text and textile so familiar to medieval writers. What I here call the "textile logic" of romance opens out onto two further, related considerations. First, romances are themselves replete with textile objects (gloves, cloths, clothing) that form an important part of their fabric of reality. The fourteenth-century romances Sir Degaré, Sir Degrevant, and Emaré all exemplify the importance of various textile objects in romance networks of agency. Second, in the various forms of stitching and fabric required to produce and maintain a manuscript, these objects emerge as "systems of fabric" in both material and figurative senses. I argue, therefore, for the importance of understanding romance textuality as fabricated or woven in a number of senses. The work of Bruno Latour, Michel Serres, and Tim Ingold — replete with recourse to textile figures and metaphors — forms a central theoretical thread for the discussion.

Keywords: textiles, textus, manuscripts, romance, Michel Serres, Bruno Latour, agency.

voile, toile, tissu, chiffon, étoffe, peau de chèvre ou d'agneau, dite parchemin, cuir écorché d’un veau pelé ou dépouillé, dit vélin, papier souple et fragile, laines ou soieries, toutes variétés planes ou gauches dans l'espace, enveloppes du corps ou supports de l'ecriture, pouvant fluctuer comme un rideau, ni liquid ni solide, certes, mais participant des deux états. Pliable, déchirable, extensible ... topologique. (Michel Serres, Atlas 45)

veil, canvas, tissue, chiffon, fabric, goatskin and sheepskin, called parchment, hairless or bare hide cut away from a calf, called vellum, soft and fragile paper, wool or silk, all the forms of planes or twists in space, envelopes for the body or writing supports, able to flutter like a curtain, neither liquid nor solid, certainly, but participating in both conditions. Pliable, tearable, stretchable ... topological. (my trans.)

Medieval romances are replete with references to their textual predecessors, the previous works from which new narratives are compiled. The anonymous fifteenth-century work The Squire of Low Degree well exemplifies this propensity. Early in the poem, the "squyer of lowe degree," who will become its protagonist, retreats to a garden to lament the fact that he is not the equal of those romance heroes of which he has read or heard: "Sir Lybius" (of Lybeaus 
Desconus), “Syr Gawayne,” and "Syr Guy” (78-80). ${ }^{1}$ Hearing his laments from her chamber overlooking the garden, the princess, whom the squire wishes to win, opens one of the windows of her "oryall” (93; windowed recess) in order to berate him, encouraging the squire to embark on a series of quests to prove his worthiness. These windows, we are told, are "fulfilled ... with ymagery” (95). Their content is not specified, but, in this context, "ymagery” suggests that the windows contain figures from secular narratives; as is discussed in further detail below, romances frequently contain figurations of their textual predecessors woven in fabric, jeweled in precious stones, or painted onto walls. In a moment of metatextual aperture, the princess of The Squire of Low Degree opens a window painted with narrative in order to enact an equivalent opening in the new narrative the reader holds in their hands. The princess then proceeds to detail for the squire the things he must do to win her love; effectively weaving the story of her own winning by the squire, the princess's speech summarizes most (though, importantly, not all) of what is to come in the following narrative.

In a recent introductory essay to popular romance, Christine Chism utilizes textile metaphors to characterize its capaciousness: romance is "extremely flexible” as a genre, "its repertoire alters over time as romance writers discard, patch, and adapt their conventional materials” (57). Chism's comments evoke the shared Latin etymology of text and textile in textus (the texture of a work, or, in a literal sense, that which is woven) and texěre (to weave), so familiar to medieval authors and readers (OED s.v. "text”). Variously patched up and adapted by largely anonymous writers over time, the fabric of romance produces new works in a textile economy of use and reuse. The notion of conjointure, the weaving of new text from diverse existing materia, provided a way for medieval authors to imagine what was shared between weaving and writing as ways of making new text (Wright 11-14). In turn, a critical tradition of conceptualizing medieval romances as woven objects has developed. Eugène Vinaver's influential work on romance was perhaps the first to formulate the comparison between weaving and writing as aesthetic forms in detail. In Form and Meaning in Medieval Romance, Vinaver describes romance texts as tapestries because the processes required to produce both create meaning through the establishment of formal and thematic patterns (12). The connection between the composition of romance and weaving is not just metaphorical and etymological, then, but is also based on shared methods of production. Romance, like tapestries and other woven objects, is dependent on replicating patterns, both structurally and aesthetically.

Drawing on Vinaver's work, Monica Wright has also recently discussed the "structural similarity between the weave of cloth and romance narrative," with particular reference to French romances of the twelfth century and the importance of textile objects and clothing to their narratives (6). A number of Middle English romances, including The Squire of Low Degree, evince what, following and expanding on these studies, I here call the "textile logic" of 
romance. Central to such narratives is the self-conscious folding or weaving of romance figures and their exploits into new works, in which the old stories told in books or other written surfaces become interwoven with the new stories protagonists tell about themselves; or, a sense in which material objects depicted within the narrative function simultaneously as a figure of that narrative. The fabric fold or gathering as a metaphor for medieval romance composition provides an effective way of conceptualizing the selfreflexiveness of many of these works: both dense with the threads of existing materia and open to self-conscious and metatextual acts of recombination, the fabric of romance is especially "pliable, déchirable, extensible” (Serres 45).

Thinking of romance in terms of fabric and its potential gatherings, folds, and other alterations leads to thinking about those textile objects that appear in these works: the gloves of Sir Degaré, the "towellus" that seem to flow like waves across a table in Sir Degrevant (1401), and the glittering woven cloth of Emaré, to take just three notable examples. ${ }^{2}$ These three examples form the basis of my discussion of the agency of textiles in the first section below. Each is indicative of how textile objects in romance frequently exhibit what J. Allan Mitchell calls "tenacity": these things "are not just immaterial effects; they are effective materials that join up with others in the collective" (118). In a similar effort to avoid readings that "dematerialize or demolish the object in relation to human becoming," I emphasize the agency of the textiles of medieval romance, rather than seeking to reduce them to cultural props or transparent vectors of human desire (Mitchell 119). Romances are deeply concerned with human becoming, a fact readily apparent from the number of these works simply named according to their protagonist, whether in the medieval period or in later scholarship. Equally clear, though, is the irreducible entanglement of the material world with these scenes of human action and becoming, through which textile objects enter into networks of agency composed of multiple actors. "Networks of agency" is here intended to invoke the work of Bruno Latour, whose "actor-network theory," alongside the work of Jane Bennett and the object-oriented ontologies of Tim Morton, Graham Harman, and Levi Bryant, has provided an important theoretical spur in a vigorous and wideranging recent conversation in medieval studies as to the agency of represented objects. $^{3}$

Further, both Latour and Michel Serres make frequent recourse to textile images and metaphors in their attempts to theorize agency and temporality, making their work additionally apt for thinking about the various textile objects of medieval popular romance. In Reassembling the Social, for instance, Latour writes that "non-humans" should be "knitted together with the same wool" as other "social ties" (73). Serres's well-known image of a crumpled and torn handkerchief serves to illustrate his theory of time as topological rather than geometric, with the potential to fold back on itself and produce unexpected points of contact. For Serres, time itself, as revealed by objects, is "gathered together, with multiple pleats" (Conversations 60). 
It is important to emphasize, though, that it is not only textiles that enter into "networks of agency" in popular romance. Rather, they are one aspect of romance's focus on a range of objects that are not simply deployed by human subjects, but that frequently possess an autonomy of their own in what Jeffrey Jerome Cohen calls worlds of "intensified possibility" (Stone 10). Swords and rings, as well as items of furniture and other household objects all have the power to disrupt, resist, or redirect romance narratives, in a way that troubles the binary opposition of agential subject and passive object (Robertson 1069). ${ }^{4}$ However, while textiles are one type of object among many in the worlds of romance, it is my broader contention that they are unique in the sense that they lead us outwards (or perhaps rather onwards) to the material object that is the medieval manuscript. Manuscripts are sewn objects, dependent on fabric and stitching in their construction and maintenance, that could also accrue further textiles in their passage through the hands of later owners and users: stitched bindings, sewn or embroidered parchment repairs, fabric bookmarkers woven into folios, and fabric covers and book bags all provide a counterpoint to considerations both of the various textile objects of romance and textile metaphors for their composition. In the two sections below, I follow the threads of romance textile logic both inwards to the textile objects of romance and their efficacy in a number of narratives, and outwards or onwards to a discussion of the fabric of the medieval manuscript and the additional textile objects they could accrue over time. ${ }^{5}$

\section{Fabric's Agency}

It is difficult to think of a medieval romance that does not include some mention of clothing or other textiles. Even in those romances in which description is kept to a minimum, clothing is afforded a certain importance as an indication of nobility. In the 771 lines of the thirteenth-century romance Sir Isumbras, for example, the descriptions of clothes in terms of their quality or color are among the few details supplied beyond the poem's economical recounting of Isumbras's fall, penance, and reunion with his family. ${ }^{6}$ Elsewhere, the deployment of clothing by way of disguise provides a failsafe way to avoid notice or detection. In Havelok the Dane, the eponymous hero is particularly sensitive to the increments of status represented by dress: whether as (supposed) fisherman's son, apprentice cook, and then, having returned to Denmark, merchant, Havelok makes sure to be suitably arrayed. ${ }^{7}$ Medieval romance frequently examines the ways in which clothing might become character; in a number of works, human identity is quite literally explained from Latin ex-planer "to unfold" - to romance characters. ${ }^{8}$

Medieval sumptuary legislation — both civic and ecclesiastical — provides one much-discussed historical context for the interest romances show in clothing. Through this practice medieval lawmakers appear to have sought a clear relationship between moral inside and material outside. As Kellie Robertson argues, this desire has been replicated in a broader sense by various 
post-Enlightenment critics who have read medieval texts through a similar logic, to the detriment of so many premodern things:

Post-Enlightenment common sense encourages us to view things as inert, mute witnesses to the life of active agents, to train our attention on the human subjects who look at, move around, and organize nonhuman things. Premodern things have no such reticence and premodern subjects are often shown to be at the mercy of 'their' things. (1063)

While "historical discourses" such as sumptuary legislation and estates literature provide important context, they "leave largely unanswered the arguably more central question of how medieval people envisioned their relationships with everyday things" (1061). Robertson's comments on the recent theoretical turn to things are especially productive in thinking about medieval textiles, particularly as they appear in romance. In fact, Robertson's own central example is the "Flaundryssh bever hat" worn by Chaucer's Merchant in The Canterbury Tales (I. 272; Flemish beaver hat). ${ }^{9}$ Rather than reading this textile object as a transparent indicator of a character's inner disposition, Robertson considers instead how we might talk about characters in literary texts being "conjured" or summoned by these objects, and of how, in doing so, they draw into question the distinction between a social world of humans and a natural world of things (Robertson 1061-62).

Three fourteenth-century romances include textile objects that further invite this type of approach: like the Merchant's hat, the textile objects of Sir Degaré, Emaré, and Sir Degrevant lead us not simply or solely inwards towards the psychology of individual characters, but also outwards to the vexed question of where the line between subjects and objects is to be drawn in medieval narrative. Medieval romance is receptive to such theorizations not because subjects can be made suddenly to disappear under the weight of their things, but rather because they are often shown to be dialogically produced in and through various networks of agency (Robertson 1060). ${ }^{10}$ Latour's comments on the role of objects as mediators are especially pertinent in this context. In his essay “The Berlin Key,” an actor-network theory case study of a particular object, Latour emphasizes that such objects cannot simply be thought of as intermediaries in the making of the social. Instead, their role is constitutive and is connected to the specific properties of objects and the particular affordances of the materials out of which they are made ("Berlin Key" 18-19). As Jonathan Gil Harris astutely summarizes, mediation for Latour does not, therefore, "entail...an intermediary medium of transmission between two preexisting entities such as subject and object"; instead, "mediation materializes networks of agency comprising multiple actants (whether humans, animals, things, or knowledge systems), which collectively produce something different from what any of their components can do alone” (181). The gloves of Sir Degaré are indicative of this conjunctive power of objects, as they emerge as integral 
to narratives of human action and becoming. Sir Degrevant includes a wider array of textile objects that further exemplify how textiles come to substantiate the social and cultural. Finally, the metatextual cloth of Emaré parallels and further draws out considerations raised in Degaré and Degrevant, both in terms of the agency of the fabric objects of romance and also of how such objects function as self-reflexive figures of their own textual predecessors.

Sir Degaré survives in six manuscripts, with the now incomplete Auchinleck (National Library of Scotland MS Adv. 19.2.1) version likely the earliest. Drawing on a wide range of sources and analogues, including the Legend of Pope Gregory and a number of Irish tales, Degaré invokes a number of textual traditions. At the start of the poem a princess is raped by a mysterious redrobed knight and later gives birth to a son. Abandoning this son so that her widowed, overly-attentive father will not discover she is no longer a virgin, she includes in his cradle quantities of gold and silver, alongside a pointless sword and a pair of gloves. Both the sword and the gloves were given to her by her "lemman," the knight, though not at the same time: the gloves were sent to her later from the "fairi land" (195). These gloves, we are told, will fit only the princess's hands (196-98) and are accompanied in the child's cradle by a note stating that he must place them on the hands of any woman he marries before they consummate their vows. Degaré carries the gloves with him from infancy. At the age of twenty, after his initial exploits as a knight, Degaré unknowingly returns to the place of his birth to find the King still insisting that suitors of his daughter must defeat him in a jousting competition in order to prove their worth. Degaré proceeds to win the hand of the princess in a duel with her father; by contrast to Oedipus, the medieval Judas Iscariot, and Pope Gregory though, Degaré averts his apparent fate as he remembers that he must try the gloves on the hands of his bride, who immediately realizes their significance. Redirecting the narrative, the gloves initiate the second stage of Degaré's quest: having found his mother, the young knight continues his search for his father. The poem culminates in a battle between father and son; failing to recognize each other at its outset, Degaré's father realizes the identity of his opponent when Degaré brandishes the pointless sword that had also been left in his cradle.

The symbolism of the gloves and the sword in concert seems clear: the feminine garment counterpoised by the phallic device of the sword. However, there is more to say about the gloves in the terms I have emphasized in my brief summary of the narrative above; that is, in terms of what the gloves do, rather than what they might mean. Their ultimate origins unknown beyond their being a gift from the fairy knight, the "enchanted” gloves of Sir Degaré possess an autonomy that is never entirely integrated into the poem's broader narrative arc. ${ }^{11}$ These gloves are described as being sent to the princess from 
the "fairi land" (195), rather than being given to her along with the knight's sword earlier in the narrative. Taking their absence from this initial scene as indicative of the poet's limited skills, George P. Faust suggests that the gloves were a late addition to the narrative of Sir Degaré: their lack of integration in contrast to the sword makes them seem like an afterthought (81). Whether Faust's explanation is accurate or not on its own terms, it largely ignores the fact that the gloves are particularly "effective materials": when they suddenly reappear in Degaré's hands later in the poem, they become constituents of a new network of agency, through which the social fabric of the court is guaranteed not by human cognition or memory alone, but also by a material object. The gloves can only be brought back into the narrative by Degaré, but once there they become mediators in the sense described above, achieving something they could not accomplish alone but that, equally, could not take place without them. And although their timely reappearance redirects the narrative, the gloves of Degaré also serve to remind us that " $[\mathrm{t}] \mathrm{he}$ materialization of social connection through gloves was always threatened by the contingency of things: the gloves might not fit; they were easily lost (like handkerchiefs); they wore out and got stained” (Stallybrass and Jones 119). Their enchanted nature dictates that they will always fit the princess's hands, but the gloves of Degaré — belatedly appearing in the narrative, unworn for twenty years yet apparently always accompanying the poem's protagonist are indicative of the contingency of the temporary assemblages of romance, which gather human and nonhuman actors alike.

While the narrative of Sir Degaré turns on the reappearance of a pair of gloves, other romances turn their attention to a wider range of things. The tailrhyme romance Sir Degrevant includes a variety of textile objects, most notably its richly-arrayed clothing, table coverings, and embroidered cloths. Degrevant is preserved in two fifteenth-century manuscripts: the Lincoln Thornton manuscript (Lincoln Cathedral Library MS 91) and the Findern manuscript (Cambridge University Library MS Ff.i.6). Copied by Robert Thornton, the former includes eighty texts over 314 folios, with the nine romances in the manuscript all occurring in the opening sequence of fifteen texts. CUL MS Ff.i.6 was copied and compiled by the Findern family of Derbyshire in the second half of the fifteenth century. The manuscript is a collection of works by John Lydgate, Thomas Hoccleve, and Chaucer, alongside a history of England and a number of lyrics. Sir Degrevant details a series of confrontations between its eponymous hero and his neighbor Sir Sere of Cyprus (always referred to as “the Earl”), Degrevant's courting of Melidor (the Earl's daughter), and, finally, the Earl's acceptance of Degrevant as Melidor's suitor after the urging of the Earl's wife. Such a summary provides only an outline of the material of the poem, though, for Sir Degrevant is also a remarkable gathering of objects; it is a work noted for its interest in the materials of castle and courtly life and the largely French-derived vocabulary used to convey this markedly object-oriented narrative. W. A. Davenport notes 
the number of these terms that only occur elsewhere in building manuals, inventories, and wills (117). Along with Degrevant's other objects, the embedded references to such texts provide "glimpses of the material elaborations of culture," making clear the dependence of human life on numerous objects and materials, with their complex ecologies, unique affordances, and inhuman lifespans (Mitchell 119). Linking literary narrative and these household or instructional texts, Degrevant is a work that is, at points, seemingly as interested in the ways in which a diverse array of things substantiate the human as it is in the actions and motivations of its protagonists.

Late in the poem, having defeated the Earl's preferred suitor of his daughter and been accepted by Melidor herself, Degrevant is admitted to the castle. At this point in the narrative, as at others, the reader is confronted by a varied array of objects. In one sense, of course, the numerous objects of the castle are an index of Melidore's inherited wealth and status. Yet she is also in effect obscured, and the narrative almost derailed, by this "superabundance of things" (Robertson 1069). The narrator emphasizes how "ter” (1425; difficult) it would be to describe accurately all of the food later served to Melidor and Degrevant, but this is a disclaimer that might have been made on a number of other occasions in the poem. The "bourd of yvore" at which Degrevant and Melidor will be served these copious amounts of food and wine is covered with a double layer of textiles:

Clothus keverede that [the table] ovur -

Swyche seye thei never are.

Towellus of Eylyssham,

Whyghth as the see ys fame,

Sanappus [overcloths] of the same,

Thus servyd thei ware. (1399-1404)

The layers of textiles on the ivory table are described as "Whyghth as the see ys fame” (white as the sea's foam). The metaphor of sea's foam suggests not only the pristine whiteness of the fabric, but also that it appears to flow unbidden like waves across the flat surface of the table, a description that evokes Serres's description in Atlas of fabric as topological, rather than geometric, in its pleats and folds (45). This metaphor is also a repetition of an earlier description of Melidor herself, who is also described as "Whyeght as the seys fame” (562).

Further, the fabric of the tablecloth is localized to a particular place, through which the romance world of the poem and the contemporary present of its writing and circulation are gathered together: "Eylyssham" refers to the Norfolk village of Aylsham, famous for its linen production in the fourteenth and fifteenth centuries. ${ }^{12}$ As in the poem's lexical alignment with building manuals, inventories, and wills, Degrevant, here, looks beyond its own 
fictional boundaries as cloth further layers diverse places, times, and discursive registers. A particularly finely rendered instance among Degrevant's gathering of objects, the "towellus" are indicative of the conjunction of "effective materials" that constitutes the matter of romance (Mitchell 118). The castle also includes a textile object depicting romance narrative: in a combination of fabric and precious stones, the story of "Ydoyne and Amadas" is "perreye" (1489-95; jeweled) in the border of the canopy surrounding the bed in Melidor's chamber. Sir Degrevant figures its own textual predecessors within the fabric of its narrative, reminding its readers (and perhaps also its protagonists) what kind of story is unfolding.

Sir Degaré and Sir Degrevant well exemplify the potential importance of textiles to romance narrative. In the fourteenth-century "Brytayne laye," Emaré, a textile object is even more integral to the unfolding narrative (1030). In this instance, a woven cloth depicting four pairs of literary lovers becomes the central object of the narrative. Though predominantly characterized as a Constance-type narrative, Emaré is indicative of the pliability or alterability of the fabric of romance: lacking any scenes of courtly conflict characteristic of chivalric romance, or the divine intervention characteristic of religious narratives, it is a poem that largely refuses any overly definitive statement of generic affiliation (Scala 225-26). Further, and despite its self-designation as a "Brytayne laye," Emaré's cloth encodes a complex, reflexive relationship between the poem and its status as a written text. This relationship is intimately connected to the poem's survival in a single manuscript, the fifteenth-century household anthology London, British Library MS Cotton Caligula A.II.

As Elizabeth Scala and Anne Laskaya and Eve Salisbury have noted, the description of the cloth occupies nearly a tenth of the poem's length: ninetyeight of its 1035 lines are given over to the description of this richly decorated object, after which the narrative of Emaré's double banishment and final reunion with her husband and father is recounted at pace (Scala 224; Laskaya and Salisbury 149). This cloth is explicitly rendered as a compilation of secular romances: it contains figurings of "Ydoyne and Amadas," "Trystram and Isowde," and "Florys and Dam Blawncheflour." Finally, "In the fowrthe korner was oon, / Of Babylone the Sowdan sonne, / The Amerayles dowghtyr hym by. / For hys sake the cloth was wrowght; / She loved hym in hert and thowght, / As testymoyeth thys storye" (133-62; emphasis added). The cloth links wellknown romance narratives with the son of the Sultan of Babylon and the "Amerayles dowghtyr," the latter of which made the cloth over the course of "seuen wynter[s]" (118). The emir's daughter weaves herself into a romance text, setting Emaré in a "generic frame," against which the unfolding events of the text might be compared (Scala 227). However, the cloth's origins in the East are not just occluded, but violently suppressed and superseded by the exchanges that transfer it to the emperor's and then Emaré's possession. It was woven by an emir's daughter as a gift for her beloved, a Sultan's son. The Sultan's lands were then conquered, and the cloth seized, by the father of 
Tergaunt, King of Sicily. Tergaunt's father gave the cloth to his son, who then presents it to the emperor. In turn, he has it made into a gown for his daughter. For medieval readers, the King of Sicily's intermediate role in the violent transfer of the cloth from East to West would have seemed historically fitting: the island was an emirate between 827 and 1091, when it was conquered by the Normans after a decisive battle at Palermo; under Christian rule again, Sicily nevertheless continued to bear the architectural imprint of its years as an emirate. ${ }^{13}$ With a population of skilled weavers from the Middle East, the island was also famous from the twelfth century as a center for silk weaving: Edith Rickert notes in the introduction to her edition of the poem that the cloth is similar to some of those woven in Palermo at this time (xxxi-xxxii).

In a move that appropriates eastern craft for western attire, the emperor then has the cloth refashioned into a gown for his daughter (242-43). The material of the cloth is altered as it passes from the East to become clothing for a figure who will exemplify what the poem casts as characteristically Christian faith and perseverance. However, any attempt to forget the history of the cloth can only be partial, for not only is the emir's daughter still preserved in its fabric alongside the other romance figures, but the seven years of its production is mirrored by the frequent recurrence of the passage of time in blocks of seven. Both of Emaré's voyages adrift lasts “seuen nyght and more” (326, 674), the king of Galys is away from home for seven years (733-44) and then mourns for Emaré and his son for another seven (815-16). The emir's daughter, Emaré, the king of Galys, and their son are all recursively linked via the cloth through these shared periods of time - traces of the past are both woven in the fabric of the cloth itself and echoed in the poem's frequent allotment of time in blocks of seven, a replicating pattern that pleats the poem's narrative, bringing past and present actors into contact.

In turn, this focus on the work that produced the cloth and then remade it into a garment leads us to considerations of the work done by the cloth. Again, this is not an attempt to forget Emaré herself beneath the folds of her cloth, but rather to suggest ways in which, like the gloves of Degaré, the cloth mediates the networks of agency of which it becomes a part. In this context, the cloth of Emaré displays the extent to which "that ubiquitous but vague entity known as 'social relations' is not constituted by the 'social' at all but by the material things that make the social visible” (Robertson 1074). The cloth is literally "dyght" (88; ornamented) with precious gems, but also has the potential to “dighten” (MED, s.v. “dighten”; make, perform) social bonds. ${ }^{14}$ For the emir's daughter and the sultan's son the cloth is, all too fleetingly, a token of love. Between Sir Tergaunt and his father it is also a token of love, though one that has been violently removed from its scene of production. Between Sir Tergaunt and his lord, the emperor Syr Artyus, it becomes part of a performance of knightly devotion and, as a sign of betrothal, is situated "in implicit exchange for Emaré” (Scala 232). Concluding its initial exchanges, for the emperor the cloth is an object of material potentiality that, once refashioned into a gown, 
becomes a tool of (ultimately failed) sexual coercion. This refashioning of the cloth serves to redirect the narrative from its expected course as a tale of the marriage of Sir Tergaunt and Emaré.

Once in Emaré's possession, the cloth is put to more practical uses as well, as clothing under which she can shelter during her voyages adrift. Put to sea in a boat "wyth-owte anker or ore" when she refuses to marry her father, Emaré is driven by storms and wind to the coast of "Galys." Sir Kadore, a steward of the king, is out walking by the sea with two friends when he sees Emaré's boat washed ashore. "A boot [Kadore] fond by the brym, / And a glysteryng thyng theryn, / Therof they hadde ferly"; amazed, the three "went forth on the sond / To the boot, y unthurstond, / And fond theryn that lady" (349-54; emphasis added). Subject and object seem to resume their rightful places as the men cross the sand to the boat and find the "gylsteryng thyng" is Emaré. Yet the transitional and transactional space of the "brym," the seashore, is well-suited to this scene. The initial description of a "glysteryng thyng" evokes the various Middle English meanings of that word: an object or compound of elements, but also a person, and an event (MED, s.v. "thyng”). This proliferation of meanings reflects the poem's broader interest not just in how a material object circulates between human actors, but also of how it might come, arguably like all clothing, to occupy a threshold between subject and object. ${ }^{15}$

Emaré emerges changed from this scene on the beach: disguising her royal status, she tells the men her name is "Egaré" (373; "the lost one”). At the court of Galys, her return to health after her ordeal is marked by her instruction of others in the art of weaving. In her role as weaving instructor (and maybe even creative writing instructor), Egaré ensures that the court is filled by a proliferation of yet more textile "thyngs" (376-79). The fabric of romance always produces more text. Egaré eventually marries the King of Galys, but after a plot by his mother is cast adrift at sea again; this time both her and her young son shelter beneath the cloth as they drift for another seven days and nights. The "thys storye" of the earlier description of the cloth comes to refer to more and more text as the narrative progresses (162).

Emaré models the movement between the textile objects of romance, romance texts, and the textile object that is the medieval manuscript that forms the broad thesis of the current discussion. As Elizabeth Scala has compellingly argued, as a romance compilation and dazzling lapidary in its own right, the cloth is both an important actor within the text and, beyond these "fictional boundaries," a "figure of its own textual complexity" (Scala 227). Further, the "textual complexity” figured by Emarés cloth is particularly suited to the increasingly sophisticated merchant class book-owners of the late fourteenth and fifteenth centuries. A number of late-medieval romances are found in small, relatively unadorned household anthologies like that in which the sole copy of Emaré survives. While relatively inconspicuous in their appearance, such manuscripts encode complex ideas about the creation of narrative and the books in which they circulate. Offering a story of the production of a romance 
text, the cloth figures a specifically textile logic through which the production of the cloth, Emaré itself, and the manuscript are linked (Scala 227). The cloth therefore functions on numerous interpretive levels: within the story of Emaré's seven-year ordeal it gathers fabric, gems, humans, and narrative alike as it finds its way to, and then accompanies, the poem's female protagonist. Moreover, though, in a move that links the textile object of the cloth with the sewn object that is the manuscript, the narrative of the cloth's production and circulation serves as what Robertson, following Scala, calls a "metacommentary" on the circulation of romance and Cotton Caligula MS A.II itself (Robertson 1069). ${ }^{16}$

\section{Woven and Stitched Pages}

The textile objects of Sir Degaré, Emaré, and Sir Degrevant are not simply supports for, or witnesses to, the actions of human protagonists, but rather help constitute the very fabric of reality of the remarkable worlds of medieval romance. Further, all three texts are indicative of the pliability of the fabric of romance itself - each combines varied materials in a manner that well exemplifies the generic and discursive capaciousness of late medieval romance. Replicating patterns are integral to each poem, structurally, formally, and aesthetically. For medieval authors and readers the Ovidian figures of Penelope and Philomela provided important classical precursors for ideas of the textile generation of text and, as is discussed briefly above, for medieval writers, the making of romance is a process of conjointure, of the weaving of materia into new texts.

In this section I focus on an even more literal sense in which medieval writing can be thought of as the result of sewing or weaving. The late medieval anthologies in which Sir Degaré, Sir Degrevant, and Emaré survive are, like all manuscripts, structurally dependent on sewing and thread. Further, additional folios, quires or booklets, as well as bookmarkers or technical apparatus such as volvelles, might be added to a manuscript through sewing. Alongside writing in margins and other spaces, such additions attest to the fundamentally unfinished nature of medieval books, to their openness to various forms of further inscription and addition, carried out by pen and needle alike. $^{17}$

For the late medieval and early modern periods, the relationship between texts and textiles was not only one of shared lexical materials and methods of production, but also one of shared physical processes and materials. The production of paper, a substrate increasingly available from the fourteenth century, was closely linked to the real and symbolic economies of textile production and use. As Joshua Calhoun writes, "until wood pulp replaced rags in papermaking, writers and readers actively participated in a material network of textiles and texts" (335). Like the ragged leaves of books and unbound or loosely bound booklets, clothes and other textiles were recycled to produce yet more writing materials in a looping ecology of textual production and 
consumption.

The structural use of sewing and stitching in the construction of manuscripts is well known to all those who have handled them. Manuscripts are the location for more or less elaborate forms of threading and sewing as quires are linked to each other through stitching and then sewn to cords or thongs, which could then be threaded into wooden boards (Clemens and Graham 50-51). This structure can be seen in New Haven, Beinecke Library MS Osborn fa50, a fifteenth-century manuscript of Peter Idley’s “Instructions to his son,” which still includes its original wooden boards (Figure 1). End-bands of leather, parchment, hemp or linen strengthened the attachment of the joined quires to the boards. Compound end-bands included an additional decorative layer of stitching in silk or other thread. ${ }^{18}$

\section{Figure 1}

Limp bindings of paper, parchment or fabric wrapped, tacketed or roughly stitched around a number of quires or booklets were also common in the late medieval period and into the early modern age. For instance, the "Book of Brome” (New Haven, Beinecke Library MS 365), a fifteenth-century paper miscellany, still includes its original limp binding. Rather than being sewn onto cords, the five quires have been sewn directly into the spine. The long vertical stitches also attach a rectangular piece of leather to the vellum wrapper, for further strengthening and protection (Figure 2).

\section{Figure 2}

As Alexandra Gillespie notes, such books could be compiled in rooms like the one where the narrator of Chaucer's House of Fame works on his "rekenynges" (653); for a "poet-bureaucrat" like Chaucer, such limp-bound books "may have proved as handy for drafting poems as for totting up accounts” (Gillespie 168). Lacking the protection of a solid binding in easily altered or dispersed assemblages, it is salutary to think of how many of these relatively low-cost manuscripts, perhaps containing romance works, might have been read to pieces during the fifteenth and sixteenth centuries. ${ }^{19}$

The maintenance of manuscripts also required sewing and textiles. Fragments of cloth and linen were used to reinforce spines and holes in parchment folios were sewn closed, a process that could also take place immediately after the skin had been stretched in the initial stages of production (Clemens and Graham 13). A folio from an early fifteenth-century manuscript of The Book of Sir John Mandeville contains a good example of this type of repair, one of many visible in the manuscript. In this instance, the repairs were clearly made prior to the copying of the text, though the original thread has been removed at a later point (Figure 3). Sewn parchment repairs of this type are a reminder that the medieval folio has a prehistory as the skin of an animal, 
and that this "dead animal is the 'con-text' of medieval literary production in the most immediate way: that with which writing is joined or woven inseparably together in and as text” (Holsinger 619).

\section{Figure 3}

Parchment folios could also be sliced and re-sewn to flatten the natural buckling that occurred in those sheets made from the skin originally covering an animal's spine. Scribes could also join together loose fragments of parchment with thin stitching to produce whole sheets, or sew singletons into existing quires in order to provide additional space for text, a process reflected on towards the beginning of The Book of Margery Kempe. The second proem at the start of The Book concludes with a passage that encompasses both textual composition and the material construction of the original manuscript itself. This proem, we are told, was composed on a loose sheet that was then added to the first quire of The Book: "whan [the scribe] had wretyn a qwayr, he added a leef therto, and than wrot he this proym”. ${ }^{20}$ Like assembling a garment or fabric wall hanging of multiple parts, leaves could also be added after another individual had finished working on an illumination or miniature.

The sewn object that is the manuscript could also acquire further textile objects over time. Sewn into the fore-edge of pages, tabs of knotted parchment or fabric could be used to mark particular folios or specific passages. More elaborate bookmarkers made of silk or linen and sewn into the headband of the manuscript were also used for this purpose. "Multi-strand bookmarkers" incorporated numerous braided or woven fabrics attached to an anchor that sat at the top of the manuscript's pages (Swales and Blatt 147-55). The surviving examples range from relatively simple combinations of a wooden peg and linen tape, to elaborate silk tapes anchored with a cast silver bar. Midway on a cline between tabs and multi-strand bookmarkers, single ribbons of silk, parchment or linen could be sewn into the page at the fore edge as relatively permanent markers of particular sections or passages (Swales and Blatt 148-54). Woodcut illustrations, pilgrim badges, and other small objects could be sewn into the pages of medieval and early modern books. Sewing was not only structurally integral to medieval literary production, but was also a form of readerly engagement. This link between pen and needle, both of which would have been employed by scribes and book-owners, is further reflected in the various "interlace" designs in the folios of manuscripts that seem intended to emulate or evoke thread and fabric (Gruber 28-29). Less elaborate versions of such designs were also used to fill space when a line did not reach to the right margin: on fol. 15r of Oxford, Bodleian Library MS Rawlinson D.652, a manuscript of The Book of Sir John Mandeville, this type of design has been used to fill roughly a third of a line before the beginning of a new chapter (Figure 4). 


\section{Figure 4}

To return briefly to bindings, various types of fabric covering could be added to manuscripts after their copying and assembly. Unfortunately for modern scholars interested in these fabric bindings or covers, many were removed from the manuscripts they once clothed in the sixteenth century, due largely to books increasingly being stored upright rather than flat in libraries (Gillespie 151). Some examples do survive, though, and the presence of multiple sewing stations in the gutter of surviving manuscripts also signals at least the possibility that they were once covered by additional materials. "Chemise" bindings were used as a primary or secondary cover for books: extending from the inner boards over the fore-edge of the book, and often fastened with straps that passed through slits made in the material, these covers enveloped the book in further stitched materials. New Haven, Beinecke Library MS 27, a fifteenthcentury copy of the Speculum humanae salvatoris, still includes its original chemise covering (Figures 5a and 5b). In this instance, multiple pieces of two separate skins have been joined through stitching and then attached to the inner boards of the manuscript through the construction of pockets (Gillespie 152). As in the Beinecke example, chemise bindings were often produced from the tawed skin of cows, goats, and sheep. However, such covers could also be made from soft textiles: Frederick Bearman has discussed two examples now held at the Walters Art Gallery (Baltimore, Walters Art Gallery MSS W.294 and W.480). Both manuscripts, a French Book of Hours and a Florentine manuscript, were produced around 1500, and both are covered with crimson velvet (Bearman 163).

\section{Figures $5 a$ \& $5 b$}

Michel Serres's meditation on the shared properties and fluid dynamics of fabric and writing supports, that forms the epigraph to this essay, eloquently articulates the physical and conceptual overlap between these two "[p]liable, déchirable, extensible” (45; pliable, tearable, stretchable) materials, in a manner that medieval writers and readers would likely have appreciated. As the examples above exemplify, the production and maintenance of medieval books can be thought of as a weaving together of diverse materials - wood, plant matter, animal skin, and a range of other materials are all joined to produce the location in which writing can take place. Alongside the metaphor and structural analogy of weaving for textual composition, the processes of sewing utilized in the production and maintenance of the medieval book remind us that medieval textuality is fabricated in a number of senses, encouraging us in turn, I would argue, to dwell for slightly longer at that threshold where materials become medium.

The work of anthropologist and theorist Tim Ingold has provided an important theoretical framework for my approach in this respect. In a series of 
essays Ingold emphasizes that materials have particular affordances and properties, qualities that are often forgotten in studies of "material culture" that focus on the coherence of finished, complete objects - and an attendant sense of their "common essence" - rather than on their production ("Materials Against Materiality” 26). In fact, two of Ingold's main examples in his essay "Materials Against Materiality” are medieval ink and manuscripts. Ink, as Ingold details, is "derived from the unlikely combination of ingredients from an astonishing variety of sources"; to be put to use, this ink requires yet more materials: a pen "made from the feather of a goose, crow, or raven, and parchment prepared by a lengthy procedure from the skins of calves or goats" ("Materials Against Materiality" 25-26). Humans, Ingold emphasizes, must work in combination with the materials before them: "skill," such as that required to produce and then join all the components of a manuscript, "is not just the mechanical application of external force, but — as exemplified in weaving - involves qualities of care, judgment and dexterity" ("Making Culture” 64). “[C]are, judgement and dexterity” are necessitated and honed not just by professional (or amateur) pride in the results of one's labor, but predominantly by the particular affordances and resistances of the materials upon which that labor works. Medieval scribes and bookmakers did not work through their materials, but with them, and their results (like those of anything we do) could never be exactly as they intended. ${ }^{21}$

\section{Conclusion: Textile Thinking}

In a characteristically allusive passage in the seventh chapter of Rome: the Book of Foundations, Serres differentiates between what he calls "boxthought" and "sack-thought." "I believe," Serres writes, "that there is boxthought, the thought we call rigorous, like rigid, inflexible boxes, and sackthought, like systems of fabric.” "Let us learn to negotiate soft logics,” Serres concludes, a mode of historical thought that reflects on the interweaving of past and present, that proceeds (as throughout Rome) through conjunction, folding, and gathering, a mode of thought that is productively ambivalent about our modern investment in the "thought we call rigorous" (Rome 236). I would like to close by suggesting that "soft logics" and "sack-thought" offer a particularly good way to think and write about late medieval vernacular textuality, especially romance works and the manuscripts in which they survive. As I argued at the opening of this essay, the fabric fold or gathering provides a powerful metaphor or analogy for the composition of medieval romance. Expansive in its potential for generic overlap and self-reflexivity, the composition of romance is a process open to conjunction and addition, just as potentially limitless possibilities are enfolded within fabric.

The last two decades have witnessed a critical reevaluation of late medieval vernacular romance, with a number of studies and essay collections emphasizing the sophistication of works that have the power "to unsettle our assumptions about ... gender and sexuality, race, religion, political formations, 
social class, ethics, morality and aesthetic distinctions” (McDonald 17). ${ }^{22}$ Moreover, these texts evince both a generic pliability and a propensity to "thematize the tribulations of literary transmission and the exigencies of their own copying, compilation, and performance” (Chism 59). Raluca Radulescu and Michael Johnston have both recently sought to consider in further detail the links between romance textuality and the manuscripts in which they survive. ${ }^{23}$ While my own approach diverges from theirs in many ways, we do share a broad interest in how various types of "manuscript evidence" might be read in combination with romance works (Johnston 303).

The manuscripts in which many romances survive are themselves more like open bags — stitched together, woven, expandable, alterable, combinable than "rigid, inflexible" boxes or containers, into which texts are placed or stacked. The compilation of anthologies such as BL MS Cotton Caligula A.II, the Auchinleck manuscript, and the Findern manuscript might be described as proceeding via the sort of "soft logic" Serres details: these are processes of gathering and shaping, in a mix of prior planning and contingent alteration and addition over time, through which romances often became part of generically diverse assemblages. The numerous forms of stitching required in the production and maintenance of a manuscript - as well as the addition of fabric covers and other objects - further materialize this mode of thought. Various materials are sewn, stitched, or woven together in the process of becoming a manuscript, making these objects "systems of fabric" in a number of both literal and figurative senses.

Finally, the "soft logic" of the fabric fold or gathering provides a model for critical activity itself. As Jonathan Gil Harris writes, folding Serres's figure of a torn and crumpled handkerchief into his own discussion of the disruptively agential handkerchief of Shakespeare's Othello, we might think of critical activity as a "forging of nonlinear connections between past and present" (Harris 174). The work of Serres, Latour, Ingold, and Harris provides a good way of discussing the fabric objects of romance and their roles as constituents of various networks of agency, as well as the materials of medieval books themselves, one that forges just such a "nonlinear connection" with the medieval period's own rich vocabulary for the poetic and conceptual affordances of fabric and the act of weaving. ${ }^{24}$ Alongside, and in dialogue with, more technical discussions of the relationship between matter and form, textiles were an important mode for medieval writers to think about material substance and its transformations, particularly through reference to Boethius's Consolation of Philosophy and what Chaucer in Boece calls the "perdurable matere” of Philosophy's clothing (Book I, Prosa 1, 1. 21). My intention, then, has been to follow some of the threads of the textile logics of romance across both metaphoric and material domains. 
Thanks to Anthony Bale, Hannah Ryley, Matt Harle, Isabel Davis, Beth Robertson, Vin Nardizzi, and Jane-May Martin for their valuable comments and suggestions at various stages of the writing and revision of this essay. I am grateful to the editors of Exemplaria and to my anonymous readers for their comments and criticisms.

${ }^{1}$ All quotations are from The Squire of Low Degree, in Sentimental and Humorous Romances, edited by Erik Kooper, Medieval Institute Publications, 2005, pp. 127-71. Citations appear by line number parenthetically in the body of the text. The only complete text of the poem survives in a 1560 edition printed by William Copland. From the study of its language, scholarly consensus has coalesced around a dating of its composition to the second half of the fifteenth century (Kooper 127).

${ }^{2}$ Quotations are taken from Sir Degrevant, in Sentimental and Humorous Romances, edited by Kooper, pp. 53-126. Quotations from Sir Degaré and Emaré are taken from The Middle English Breton Lays, edited by Anne Laskaya and Eve Salisbury, Medieval Institute Publications, 1995, pp. 89-144 and 145-99 respectively. Citations appear by line number parenthetically in the body of the text.

${ }^{3}$ See, for example, Mitchell's Becoming Human, Cohen's Stone, and the contributions to the special issue on ecomaterialism edited by Jeffrey Jerome Cohen and Lowell Duckert: postmedieval, vol. 4, no. 1, 2013.

${ }^{4}$ The recent collection Medieval Romance and Material Culture, edited by Nicholas Perkins, also considers the many ways in which the objects of romance make meaning, as well as the connections between romance texts and the materiality of the manuscripts in which they are found. See also Lisa H. Cooper's "Bed, Boat, and Beyond."

${ }^{5}$ Though it is not possible to discuss them in any detail here, tapestries, wall hangings, and wall paintings made to resemble fabric provide a further thread linking textiles and medieval textual culture.

${ }^{6}$ Sir Isumbras, in Four Middle English Romances, edited by Harriet Hudson, Medieval Institute Publications, 2006, pp. 5-38 (20; 121; 249; 357; 588; 620; 752).

${ }^{7}$ Havelok the Dane, in Four Romances of England, edited by Graham Drake, Ronald B. Herzman, and Eve Salisbury, Medieval Institute Publications, 1997, pp. 73-185 (1137-47).

${ }^{8}$ See, for example, the scene in the fairy king's castle in the fourteenth-century romance Sir Orfeo, in which clothing seems to reorient and reconfirm Orfeo's perception as he attempts to navigate the strange realm of undead corpses and glittering surfaces of the fairy kingdom. Orfeo is able to identify his abducted 
wife Heurodis only "bi her clothes" (Sir Orfeo, in The Middle English Breton Lays, edited by Laskaya and Salisbury, pp. 15-59 (408)). A number of recent studies have focused on clothing and textiles in medieval narrative. In Fashioning Change, Andrea Denny-Brown discusses "the capacity of clothing to organize ideas about cultural change, something that fascinated medieval poets and their audiences” (1-2). Similarly, Nicole Smith's Sartorial Strategies examines the various "transformative properties" of clothing in romance (1). More broadly, E. Jane Burns supplies a compelling account of "the spectrum of possibilities raised by the study of medieval cloth and clothing" in her introduction to Medieval Fabrications (1). Ann Rosalind Jones and Peter Stallybrass have explored a similar line of thought in relation to early modern textiles in Renaissance Clothing and the Materials of Memory, where they emphasize the imbrication of clothing, memory, and corporeality.

${ }^{9}$ All references to the works of Geoffrey Chaucer are from The Riverside Chaucer, 3rd. ed., edited by Larry D. Benson, et al. Citations refer to line number for the House of Fame, fragment and line number for The Canterbury Tales, and book number and line number for Boece. All citations appear parenthetically in the body of the essay.

${ }^{10}$ For a timely and perceptive discussion of "the anxiety about object oriented ontology and post-humanism and ecocriticism displacing/replacing human subjects," see Anne F. Harris and Karen Eileen Overby, "Field Change/Discipline Change” (142). J. Allan Mitchell also comments on the perceived "ethical and political impartiality of posthumanist, ecological, and materialist thought," with particular reference to feminism, and offers a cogent defense against this charge (xx). In a related sense, Jeffrey Jerome Cohen argues that "a long tradition of feminist inquiry," particularly the work of Karen Barad, Stacy Alaimo, and Patricia Yaeger, is in fact "instrumental to this turn to things and substance” (Stone 39). These issues are additionally pertinent in the current context of a discussion of clothing and textiles, objects of material culture that are especially closely imbricated with issues of gender, social regulation, and cultural imagination.

${ }^{11}$ Laskaya and Salisbury describe the gloves as "enchanted," a description that aligns them with the "enchanted chestnut tree" under which the princess's retinue fall asleep at the start of the poem and the "enchanted" sleep into which Degaré later falls, and that signals towards the poem's incorporation of material from a number of Celtic sources (89-96).

12 On the poem's interest in objects and the reputation of Aylsham in the later Middle Ages, see the introduction to L. F. Casson's edition of the poem (xlvixlix).

${ }^{13}$ On the cloth of Emaré and its status as a symbol of Western desire for the

East and of projected Christian military domination, see Geraldine Heng, Empire of Magic (194-95).

${ }^{14}$ Scala also focuses on the poem's interest in all that is “dyght” (227). 
15 Julian Yates has written on a similar scene in Sir Philip Sidney’s 1586 New Arcadia, in which two shepherds witness a "thing" being washed ashore, which reveals itself to be Musidorus, the text's protagonist (9-15). In Yates's reading, which also draws heavily on the work of Latour and Serres, the text fleetingly imagines "a world not of subjects and objects but of things," in a way that resonates with the scene on the beach in Emaré (12).

${ }^{16}$ Scala notes the possibility that the Cotton manuscript was also once bound with a fabric covering, making it a textile object in a further metanarrative sense (229). However, rebound in 1957, its folios mounted on paper guards, the manuscript has been particularly distanced from its original appearance.

${ }^{17}$ Jeffrey Todd Knight has also recently written on the fabrication of early modern books, detailing both their structural dependence on sewing and stitching and also the ways in which "needle and thread were ... tools for reading, annotating, organizing knowledge, and even collaborative scholarship” (523).

18 J. A. Szirmai's The Archaeology of Medieval Bookbinding includes a number of images and diagrams of the construction of different types of end-band (160-61 and 205-7).

${ }^{19}$ However, as Gillespie cautions, the survival of a number of elaboratelystitched limp bindings complicates any "too-simple dichotomy" between robust, expensive board-bindings and cheaper limp bindings (166).

${ }^{20}$ The Book of Margery Kempe, edited by Barry Windeatt, Brewer, 2000, p. 50.

${ }^{21}$ For Ingold, however, weaving is not just an example of how humans work with materials, rather than through them. In "Making Culture and Weaving the World," Ingold elaborates on how weaving provides a way of describing more fundamentally how "the forms of objects are not imposed from above but grow from the mutual involvement of people and materials in an environment" (68). Scaling up the theoretical associations of the act of weaving, Ingold argues that we should "reverse our normal order of priorities and regard making as a modality of weaving, rather than the other way around" (64). While making implies the frictionless transformation of a malleable surface, "the prior presence of a surface to be transformed," weaving describes a "reciprocal ... dialogue” with materials, an "emergent interface” between nature and culture through which ideas and material flows are interwoven (55-57). Ingold further expands on this approach in "The Textility of Making."

22 In particular, see Nicola McDonald's edited collection, Pulp Fictions, Melissa Furrow's Expectations of Romance, and Radulescu and Rushton's coedited A Companion to Medieval Popular Romance.

${ }^{23}$ See especially Radulescu's Romance and its Contexts in Fifteenth-Century England and Johnston's "New Evidence for the Social Reach of Popular Romance.” Maldwyn Mills and Gillian Rogers’s “The Manuscripts of Popular Romance” provides a good summary of the manuscript record of Middle English romance. 
${ }^{24}$ In the conclusion to Fashioning Change, Denny-Brown also briefly considers the potential relationship between studies of medieval textiles and clothing, and the recent theoretical turn to things and a new materialism (18081).

\section{Works Cited}

Bearman, Frederik. "The Origins and Significance of Two Late Medieval Textile Chemise Bookbindings in the Walters Art Gallery." The Journal of the Walters Art Gallery, vol. 54, 1996, pp. 163-87.

The Book of Margery Kempe, edited by Barry Windeatt, Brewer, 2000.

Burns, E. Jane. "Introduction: Why Textiles Make a Difference.” Medieval Fabrications: Dress, Textiles, Cloth Work, and Other Cultural Imaginings, edited by E. Jane Burns, Palgrave Macmillan, 2004, pp. 1-18.

Calhoun, Joshua. "The Word Made Flax: Cheap Bibles, Textual Corruption, and the Poetics of Paper.” PMLA, vol. 126, no. 2, 2011, pp. 327-44.

Casson, L. F. Introduction. The Romance of Sir Degrevant, edited by L. F. Casson, Early English Text Society, o.s., 221, Oxford UP, 1949, pp. ix-lxxvii .

Chaucer, Geoffrey. The Riverside Chaucer, 3rd ed., edited by Larry D. Benson, et al., Oxford UP, 2008.

Chism, Christine. "Romance.” The Cambridge Companion to Middle English Literature, edited by Larry Scanlon, Cambridge UP, 2009, pp. 57-70.

Clemens, Raymond and Timothy Graham. Introduction to Manuscript Studies. Cornell UP, 2007.

Cohen, Jeffrey Jerome. Stone: An Ecology of the Inhuman. University of Minnesota Press, 2015.

Cohen, Jeffrey Jerome, and Lowell Duckert, editors. “Ecomaterialism”, postmedieval, vol. 4, no. 1, 2013.

Cooper, Lisa H. "Bed, Boat, and Beyond: Fictional Furnishings in La Queste del Saint Graal.” Arthuriana, vol. 15, no. 3, 2005, pp. 26-50.

Davenport, W. A. “Sir Degrevant and Composite Romance.” Medieval Insular Romance: Translation and Innovation, edited by Judith Weiss, et al., Brewer, 2000, pp. 111-34.

Denny-Brown, Andrea. Fashioning Change: The Trope of Clothing in High- and LateMedieval England. Ohio State UP, 2012.

"Emaré.” The Middle English Breton Lays, edited by Ann Laskaya and Eve Salisbury Medieval Institute Publications, 1995, pp. 145-99. .

Faust, George P. Sir Degaré: A Study of the Texts and Narrative Structure. Princeton UP, 1935.

Gillespie, Alexandra. "Bookbinding.” The Production of Books in England 1350-1500, edited by Alexandra Gillespie and Daniel Wakelin, Cambridge UP, 2011, pp. 150-72.

Harris, Anne F. and Karen Eileen Overby. "Field Change/Discipline Change.” Burn After Reading Vol.2 The Future We Want: A Collaboration, edited by Jeffrey Jerome Cohen, Punctum, 2014, pp. 127-43.

Harris, Jonathan Gil. Untimely Matter in the Time of Shakespeare. University of Pennsylvania 
Press, 2009.

"Havelok the Dane.” Four Romances of England: King Horn, Havelok the Dane, Bevis of Hampton, Athelston, edited by Graham Drake, Ronald B. Herzman, and Eve Salisbury, Medieval Institute Publications, 1997, pp. 73-185.

Heng, Geraldine. Empire of Magic: Medieval Romance and the Politics of Cultural Fantasy. Columbia UP, 2003.

Holsinger, Bruce. "Of Pigs and Parchment: Medieval Studies and the Coming of the Animal.” PMLA, vol. 124, no. 2, 2009, pp. 616-23.

Ingold, Tim. "Making Culture and Weaving the World.” Matter, Materiality and Modern Culture. Ed. P. M. Graves-Brown. Routledge, 2000, pp. 50-71.

_. "Materials Against Materiality.” Being Alive: Essays on Movement, Knowledge and Description. Routledge, 2011, pp. 19-32.

—_. "The Textility of Making." Cambridge Journal of Economics, vol. 34, 2010, pp. 91102.

Johnston, Michael. "New Evidence for the Social Reach of "Popular Romance": The Books of Household Servants.” Viator, vol. 43, no. 2, 2013, pp. 303-32.

Jones, Ann Rosalind and Peter Stallybrass. Renaissance Clothing and the Materials of Memory. Cambridge UP, 2000.

Knight, Jeffrey Todd. “Needles and Pens: Sewing in Early English Books.” Journal of Medieval and Early Modern Studies, vol. 45, no. 3, 2015, pp. 523-42.

Kooper, Erik, editor. Sentimental and Humorous Romances. Medieval Institute Publications, 2005.

Laskaya, Anne, and Eve Salisbury, editors. The Middle English Breton Lays. Medieval Institute Publications, 1995.

Latour, Bruno. “The Berlin Key: How To Do Words With Things” Matter, Materiality and Modern Culture, edited by P. M. Graves-Brown, Routledge, 2000, pp. 10-21.

—. Reassembling the Social: An Introduction to Actor-Network-Theory. Oxford UP, 2005.

McDonald, Nicola. “A Polemical Introduction.” Pulp Fictions of Medieval England, edited by Nicola McDonald, Manchester UP, 2004, pp. 1-21.

MED [Middle English Dictionary]. Consulted online at < quod.lib.umich.edu/m/med/>.

Mills, Maldwyn and Gillian Rogers. “The Manuscripts of Popular Romance.” A Companion to Medieval Popular Romance, edited by Raluca L. Radulescu and Cory James Rushton, Brewer, 2009, pp. 49-66.

Mitchell, J Allan. Becoming Human: The Matter of the Medieval Child. University of Minnesota Press, 2014.

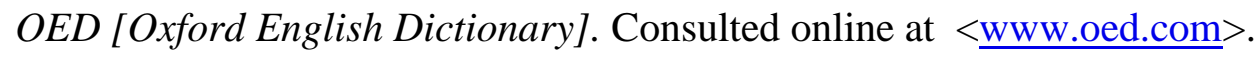

Perkins, Nicholas, editor. Medieval Romance and Material Culture. Brewer, 2015.

Radulescu, Raluca L. Romance and its Contexts in Fifteenth-Century England: Politics, Piety and Penitence. Brewer, 2013.

Rickert, Edith. Introduction. The Romance of Emaré, edited by Edith Rickert, Early English Text Society, e.s., vol. 99. Paul, Trench, Trübner, 1906, pp ix-xlviii.

Robertson, Kellie. "Medieval Things: Materiality, Historicism, and the Premodern Object.” Literature Compass, vol. 5, no. 6, 2008, pp. 1060-80. 
Scala, Elizabeth. “The Texture of Emaré.” Philological Quarterly, vol. 85, no. 3/4, 2006, pp. 223-46.

Serres, Michel. Atlas. Editions Julliard, 1994.

—. Rome: The Book of Foundations, translated by Felicia McCarren, Stanford UP, 1991.

Serres, Michel with Bruno Latour. Conversations on Science, Culture and Time, translated by Roxanne Lapidus. University of Michigan Press, 1995.

"Sir Degaré.” The Middle English Breton Lays, edited by Ann Laskaya and Eve Salisbury Medieval Institute Publications, 1995, pp. 89-144.

“Sir Degrevant.” Sentimental and Humorous Romances, edited by Erik Kooper, Medieval Institute Publications, 2006, pp. 53-126.

"Sir Isumbras.” Four Middle English Romances: Sir Isumbras, Octavian, Sir Eglamour of Artois, Sir Tryamour, edited by Harriet Hudson, Medieval Institute Publications, 2006, pp. 5-38.

"Sir Orfeo.” The Middle English Breton Lays, edited by Ann Laskaya and Eve Salisbury Medieval Institute Publications, 1995, pp. 15-59.

Smith, Nicole. Sartorial Strategies: Outfitting Aristocrats and Fashioning Conduct in Late Medieval Literature. University of Notre Dame Press, 2012.

“The Squire of Low Degree.” Sentimental and Humorous Romances, edited by Erik Kooper, Medieval Institute Publications, 2006, pp.127-71.

Stallybrass, Peter and Ann Rosalind Jones. "Fetishizing the Glove in Renaissance Europe.” Critical Enquiry, vol. 28, no. 1, 2001, pp. 114-32.

Swales, Lois and Heather Blatt. "Tiny Textiles Hidden in Books: Toward a Categorization of Multiple-Strand Bookmarkers.” Medieval Clothing and Textiles, vol. 3, 2007, pp. 14579.

Szirmai, J. A. The Archaeology of Medieval Bookbinding. Ashgate, 1999.

Vinaver, Eugène. Form and Meaning in Medieval Romance. Modern Humanities Research Association, 1966.

Wright, Monica. Weaving Narrative: Clothing in Twelfth-Century French Romance. Pennsylvania State UP, 2009.

Yates, Julian. Error, Misuse, Failure: Object Lessons from the English Renaissance. University of Minnesota Press, 2003.

\section{Note on contributor:}

Tom White recently submitted his doctoral thesis at Birkbeck, University of London. This thesis - "Potential Lives: the Matter and Materials of Late Medieval Manuscripts" - traces some of the figurative and interpretative possibilities of manuscript study, with particular reference to the materials of late medieval vernacular anthologies and miscellanies and the manuscripts of The Book of Sir John Mandeville. He also writes on ecology and sound art and is contributing editor of the Glasgow Review of Books.

Correspondence to: Tom White. Email: twhite07@mail.bbk.ac.uk 